\title{
AN OVERVIEW ON SMART FARMING - IOT IN AGRICULTURE
}

\begin{tabular}{|c|c|c|c|}
\hline & \multicolumn{3}{|c|}{$\begin{array}{c}\text { Durgesh Nandan } \\
\text { SOA, Sanskriti University, Mathura, Uttar Pradesh, India }\end{array}$} \\
\hline Journal & \multicolumn{3}{|c|}{$\begin{array}{l}\text { Samvakti Journal of Research in Information Technology } \\
\text { https://www.sjrit.samvaktijournals.com } \\
\text { Volume } 2 \text { Year of Volume } 2021 \text { Page No : } 33 \text { - } 40\end{array}$} \\
\hline Discipline & \multicolumn{3}{|l|}{ Internet of Things } \\
\hline Conference & \multicolumn{3}{|c|}{$\begin{array}{l}\text { A virtual international conference on redefining and transforming the role of higher } \\
\text { education in sustainable development }\end{array}$} \\
\hline Conference & \multicolumn{3}{|c|}{ Start Date: September 30, 2021} \\
\hline Dates & \multicolumn{3}{|c|}{ End Date : September 30, 2021} \\
\hline Institute Name & \multicolumn{3}{|c|}{$\begin{array}{l}\text { JAIN (Deemed-to-be University) in association with Council for Industrial } \\
\text { Innovation and Research }\end{array}$} \\
\hline $\begin{array}{l}\text { Date Received } \\
\text { ID } \\
\text { Dol }\end{array}$ & $\begin{array}{l}\text { : November } 19,2021 \\
: 2021.02 .14 \\
: 10.46402 / 2021.02 .14\end{array}$ & $\begin{array}{l}\text { Publication Date } \\
\text { Paper Type } \\
\text { Dol URL }\end{array}$ & $\begin{array}{l}\text { : December 11, } 2021 \\
: \text { Conference Paper } \\
\text { : https://dx.doi.org/10.46402/2021.02.14 }\end{array}$ \\
\hline
\end{tabular}

\section{ABSTRACT}

Internet of the Things is game changing technology that symbolizes future of the communications and computing's. IOT is being utilized in a variety of fields, including smart homes, intelligent traffic management, and smart cities. IoT has broad range of applications and may be used in almost any sector. The applications of IoT in agriculture is the subject of this article. Crops management, resource managements, cost-effective agricultures, increased amount and quality, crop monitoring, or fields monitoring are all possible with loT. soils $\mathrm{pH}$, Air temperature sensor, humidity sensors, water volume sensors, soils moisture sensor, and other loT sensors are utilized in the suggested model. In this research, I examined common agricultural techniques used by farmers today and the difficulties they confront, as well as visiting poly homes to learn more about innovative farming technology. The suggested models is basic architecture of the Internet of Things sensor that gather data or transmit it to a server via Wi Fi networks, where the servers may act based on the data.

KEYWORDS: Agriculture, loT, Poly House, Smart farming, Sensor, 


\section{INTRODUCTION}

Smarts farming entails use of the variation of technology or equipment's, such as the internets, cloud, or Internets of Things devices. Because the world's populations is growing, or is estimated to reach 9.8 billion by the 2050, people need to increase agricultural output to feed that billion people. Because of various factors such as the industrializations, commercial market, or residential building being build's on the agricultural land, human need to increase our productions, which can be the done by the implementing's loT in the farming. To feeds these billions, people needs to rise our productions, which can have done by implementing Internet of things in farmings. Precisions farmings is another term for smarts farming. Farmers are now unable to enjoy the fruits of their labor owing to a variety of factors including insect assaults, plant disease, a lack of understanding about necessary nutrients for crops, and other difficulties. To overcome these challenges and make farming more lucrative, smart, and pleasant for farmers, technology development is required. Precision farming and traditional farming are diametrically opposed in every aspect. Traditional farming employs ancient and traditional agricultural techniques, as well as old equipment for labor and seasonal crop production, without any prior evaluation of market demand, rates, or weather forecasts from the meteorological service, for example. Smart farming makes use of modern technology such as smart linked devices, loT sensors, the Internet, farmers' chat rooms, and ongoing assessments of different variables such as the optimum circumstances for plants to develop, the amount of nutrients required, soils quality, water excellence, and so on. Smarts farming makes farming simple, affordable (costs effective), reduces labor costs, and improves agricultural yields or output ${ }^{[1][2]}$.

\section{Model Proposed:}

\section{a. Poly Houses:}

The poly home is completely covered steels building with polythenes as the covering. This polythenes shields the crops from the damaging UV ray, heavy rain, storm, or others environmental conditions that may damage the crops or reduce output. In a poly home, farming is done in a completely enclosed and regulated environment. With the assistance of the poly farms houses, crop output and quality can be improved nearly twice as much, but there are still some methods to boost productivity, such as incorporating loT devices into the Poly House.

\section{b. A Water Volumes Sensors is a devices that detects the amount of the water:}

Water Amount Sensor is an Internet of Things devices that keep tracks of the volumes of the water running over the pipes. If we give extra water than is required, we will have poor 
production and waste water. This water volume sensor gadget sends data to the server, which then takes the appropriate action, such as turning off the pump.

\section{c. pH sensor for the soil:}

A soils $\mathrm{pH}$ sensors is a devices that detects the $\mathrm{pH}$ of soils, which is important since some crops need a certain $\mathrm{pH}$. This $\mathrm{pH}$ sensor monitors soils $\mathrm{pH}$ or transmits the information's to a servers, wherever the user may see information or apply chemical to the maintains the proper $\mathrm{pH}$ of the crops.

\section{d. Moisture Sensor for the Soil:}

Soil Moisture Sensors are similar to soil pH sensors in that they detect moisture in the soils. And the collected information is the sent to the servers, which will takes the appropriate actions, such as using spray pumps to moisturize the soils if moistures level is below what is required, or adjusting the temperature insides the poly home to bring the moistures levels back to normal if the moisture level is above what is required.

\section{e. Sensor for measuring air temperatures:}

The air temperature sensor is an Internet of Things devices that sense the temperature insides the poly home or sends the information to key server, which can then performs required operation such as turning on air conditioners, (exhausts fans, coolers, heaters, or spraying water if necessary). And this will aid in maintaining a comfortable temperature within the poly home.

\section{f. Sensor that detects motion:}

Around the field, a motion detector may be utilized poly home. These sensor detect slightly odd movements and send the data to a server, which performs an operation on the data and then sends a message to alternative devices that is likewise installed on poly home perimeter. This gadget is use to the make noises, or animal flee when they hear it.

\section{Management of Crops:}

Sensors collect data related to crops observations or transmit it to servers. If soil moisture is below the edge values, the server may take action such as watering the plants. Such operations are carried out by the server automatically, without the need for human involvement.

\section{Smarts Phone or the Internets:}

Since of low penetration of the PCs in rural households or the increasing usage of mobile phone in India, and this strategy is based on the benefits of the flexible Internets 
technologies. Client who are on the go may connect to our suggested system from anywhere at any time. Ranchers traveling or stationed in any agricultural field may access rural data. The ubiquitous, convenient, and geologically identifiables data benefits is omnipresents, convenient, or geologically identifiable. This government demonstration is expected to exceed future data scattering model. Permitting to the Web Design Statistic Reports, India's $4 G$ online coverage will reach $80 \%$ in rural areas ${ }^{[3],[4]}$.

\section{IoT Implementation Challenges:}

Sectoral Concerns the area's heterogeneity: In the food supply chain, there are a broad variety of types of performers, ranging from large (stores, seeds or information's sources suppliers, products broker) to small. As a result, no one arrangement, whether creative, business show, or administratives, will meet or satisfy all of their needs. Vineyard in the Hungary need unusual arrangement from North American arable ranchers.

Ranch size or investment cost: Larger, more capitals concentrated homestead are much more sensitive to the loT innovation adoption, and are also benefactors of the such adoption as key part of the ongoing interests in novel hardware (like tractors or ranch gears). And existing's drive intelligents cultivate mechanicals arrangement are either intend for the large homestead, such as Mr. John Deere (John DeereTM), \& works only in constrain lands space, such as Fields Views (Climates CorporationTM) or En circa (DuPontTM), which primarily serve the United States or Canada. 365 FarmNet adjusts the pricing or kinds of the services provided based on the sizes of the holdings, although its markets entry is the stills limited to the Centrals Europe ${ }^{[5]}$.

Plan of the action or business privacy: Suitable plans of the actions are needed to maintain the high degree of the secrecy or controls over information's demanded by the agriculturists, while allowing ranches as well as others agri foods on screen character to modify the informations they provide. This is a tense area, with major companies like John Deere attempting to use data captured by the equipment they provides, or agriculturists resisting however alternative loss of control and considerable value. Client and social acceptance: End user education and training are critical in helping them understand how to use and apply these novel advances. According to, $71.001 \%$ of EU cultivates heads were still workings on a ground up knowledge as recently as year ago, believing that they didn't requirement such advancements for their day to day jobs and didn't have the time to study. For non-innovatively educated youngsters, the uptake of sharp developments will undoubtedly be difficult. Regardless, there are now training and preparation efforts taking place throughout Europe with the goal of disseminating Internet of Things culture among youngsters or all partner in the natural pecking orders.

Technological Challenges Lack of the interoperability: For billions of devices to communicate, commons building blocks, information's standards, or benchmarks are 
required, and there are many suitable rules in the agrifood sector attempting to reach a general agreement. There are gauges for semantics and information presentation, agri hardware (like ISO-BUS), climatic information (e.g., SWEET), supply chain management ( EPCIS from the GS1), and online commercials retails sites (like Good Relation or Schema.org) ${ }^{[6], ~[7] . ~}$

\section{LITERATURE REVIEW}

Elijah et al. studied about the rapid growth of the world's population necessitates a move toward more efficient agricultural procedures. Food security is significant issue for the most nations because of decreasing ordinary resource, limited amounts of arables lands, or extra unpredictable weather condition. As a consequence, the Internets of Things or information analytics are being use to the improves the farming sector's operational effectiveness or production. The usage of wireless sensor networks as key driver of the smarts agriculture has shifted to use of the IoT or DA. WSN, radio frequencies identifications, clouds computing, middle ware systems, or end users applications are all part of the Internet of Things. Several advantages or difficulties of loT have been highlighted in this article. The loT ecosystem is described, as well as how the marriage of the Internet of Things with DA enables smart agriculture. they also provides future trend or prospects, which are divided into four categories: technical advances, application scenarios, business, and marketability ${ }^{[8]}$.

Malavade et al. looked into in today's world, technology has advanced significantly, and many equipment and methods are accessible in the agricultural industry. There is requirement to shift toward novel technology known as the Internet of Things in order to increase effectiveness, productivities, global markets, or minimize humans involvement, time, or costs. The Internet of Things is a networks of devices that transmits data without the need for human intervention. As a result, in order to achieve high production, IoT collaborates with agriculture to achieve smarts farming. The importance of loT in agriculture, which lead to the smarts framing, is the subject of this article ${ }^{[9]}$.

Ahmed et al. investigated how the Internets of Things adds original dimension to smarts farming or agriculture. It is the feasible to the links agricultural or farming bases located in the rural regions effectively using fog the computing or WiFi built long distances networks in the loT. They propose a scalables networks architecture for the monitoring or managing agriculture or farms in rural regions to the concentrates on the particular needs. The suggested approach lowers network latency to some degree when compared to currents the loT based agricultural and farming systems. This paper proposes cross layers channel access or routings method for sensing or actuating. On the basis of coverage range, throughput, and latency, they examine the network topology ${ }^{[10]}$. 


\section{DISCUSSION}

Smart farming incorporates a wide range of technology and equipment, including the internet, cloud, and Internet of Things (IOT) devices. We need to boost agricultural production to feed the world's increasing population, which is projected to the reaches 9.7 billion peoples by the 2050. We need to improve our output due to the numerous reason like as industrializations, commercial marketplaces, or residential structures being constructed on those agricultural areas, which may be accomplished by using loT in farming. To feed these billions, we must enhance our output, which may be accomplished via the use of loT in agriculture. Smarts farmings is also recognized as precision farmings. The Internets of Things is a game changing technology that represents communication and computing in the future. Smarts homes, smarts traffic management, or smarts cities are all examples of where the Internet of Things is being used. loT may be utilized in virtually any industry and has a broad variety of applications. The topic of this article is the use of loT in agricultures. Internet of Things allows for crops managements, resources managements, cost effective farming, enhanced quality or quantity, crops monitoring's, or fields monitoring. A smart gadget with a pump can track both the quantity of water or the time it takes for it to flow. Other agricultural domains include insecticides, fertilizers, and pesticides. We suggest utilizing loT in a poly home, which is a completely covered building with virtually no impact from outside elements such as insects, which do not enter and cannot damage the crop, thereby decreasing the need for pesticides. Sensors in the agriculturals field that are connected to the internet may be used to make an appropriate decision. Finally, because farmer play major roles in GDP in countries like India, humans must create an optimal Internet of Things architectures for the agricultural production in orders to improve quality of the products, conserve resources such as water as well as electricity, but also produce economically sound crops that cost less and make more profit.

\section{CONCLUSION}

With the use of loT devices, farming may become more efficient and precise. Agriculture may benefits from Internets of the Thing in variety of the way. The major areas are electricity or water, and their costs may make or break the agricultural profession. Water waste is far higher than we thought because of outdated leaky irrigation systems, and water pumps consume energy, therefore if we can reduce water wastages, peoples can also control electricity wastage. The amount of water and the time of flow may both be monitored utilizing a smart device with a pump. Insecticides, fertilizers, or pesticides are among the other domains in agriculture. In this paper, people propose using Internet of Things in poly home, which is fully cover structure with the almost no effects from outsides factors such as insect, which don't enters or can't harms the crops, reducing the need for 
insecticides. A suitable choice may be made utilizing sensors in the agricultural field that are linked to the internet. Finally, we must develop an optimal Internet of Things architecture for the agricultural productions in order to improve quality or quantity of productions, conserve resources such as water or electricity, as well as produced economically efficient crops that cost very little or makes more profits, as farmer play significant roles in the GDP in countries such as India. 


\section{REFERENCES:}

[1] C. S. Nandyala and H. K. Kim, "Green loT Agriculture and Healthcare Application (GAHA)," Int. J. Smart Home, 2016, doi: 10.14257/ijsh.2016.10.4.26.

[2] R. Dagar, S. Som, and S. K. Khatri, "Smart Farming - IoT in Agriculture," 2018, doi: 10.1109/ICIRCA.2018.8597264.

[3] M. Stočes, J. Vaněk, J. Masner, and J. Pavlík, "Internet of things (IoT) in agriculture - Selected aspects," Agris On-line Pap. Econ. Informatics, 2016, doi: 10.7160/aol.2016.080108.

[4] A. Rojas, "Smart Agriculture loT with Cloud Computing," Rev. Hist. América, 2015.

[5] E. Y. T. Adesta, D. Agusman, and Avicenna, "Internet of things (IOT) in agriculture industries," Indones. J. Electr. Eng. Informatics, 2017, doi: 10.11591/ijeei.v5i4.373.

[6] V. Porkodi, D. Yuvaraj, A. S. Mohammed, M. Sivaram, and V. Manikandan, "IoT in agriculture," J. Adv. Res. Dyn. Control Syst., 2018, doi: 10.48175/ijarsct-1351.

[7] M. S. Mekala and P. Viswanathan, "A Survey: Smart agriculture loT with cloud computing," 2017, doi: 10.1109/ICMDCS.2017.8211551.

[8] O. Elijah, T. A. Rahman, I. Orikumhi, C. Y. Leow, and M. N. Hindia, "An Overview of Internet of Things (IOT) and Data Analytics in Agriculture: Benefits and Challenges," IEEE Internet Things J., 2018, doi: 10.1109/JIOT.2018.2844296.

[9] V. N. Malavade and P. K. Akulwar, "Role of loT in Agriculture," Natl. Conf. "Changing Technol. Rural Dev., 2016.

[10] N. Ahmed, D. De, and I. Hussain, "Internet of Things (IoT) for Smart Precision Agriculture and Farming in Rural Areas," IEEE Internet Things J., 2018, doi: 10.1109/JIOT.2018.2879579. 